\title{
Primeira ocorrência de ferrugem em capim-limão causada por Puccinia cymbopogonis no Brasil
}

\author{
João Batista Vida ${ }^{1}$, Aníbal Alves de Carvalho Júnior ${ }^{2}$, Jaqueline Rosemeire Verzignassi ${ }^{1,3}$
}

\begin{abstract}
${ }^{1}$ UEM - Universidade Estadual de Maringá, Departamento de Agronomia, Av. Colombo, 5790, 82020-900, Maringá - PR. <jbvida@uem.br> ${ }^{2}$ Instituto de Pesquisas Jardim Botânico do Rio de Janeiro, Rua Pacheco Leão, 915, Jardim Botânico, 22460-030, Rio de Janeiro.< anibal @ jbrj.gov.br> ${ }^{3}$ Pesquisadora Capes/ProDoc. <jrverzignassi@uem.br>

Data de chegada: 06/10/04. Aceito para publicação em: 31/03/04.
\end{abstract}

\begin{abstract}
Vida, J.B., Carvalho Júnior, A.A. de, Verzignassi, J.R. First report of the lemongrass rust fungi caused by Puccinia cymbopogonis in Brazil. Summa Phytopathologica, v. 32, n. 1, p. 89-91, 2006.
\end{abstract}

It is reported the first occurrence of the lemongrass (Cymbopogon in Brazil, State of Paraná. citratus (DC.) Stapf) rust fungi caused by Puccinia cymbopogonis Mass.

Additional keywords: Cymbopogon citratus.

\section{RESUMO}

Vida, J.B., Carvalho Júnior, A.A. de, Verzignassi, J.R. Primeira ocorrência de ferrugem em capim-limão causada por Puccinia cymbopogonis no Brasil. Summa Phytopathologica, v. 32, n. 1, p. 89-91, 2006.

È registrada a primeira ocorrência de ferrugem em capim-limão (Cymbopogon citratus (DC.) Stapf), causada por Puccinia cymbopogonis

Palavras-chave adicionais: Cymbopogon citratus.
Mass., no Brasil, Estado do Paraná.

topatologia, do Departamento de Agronomia, da Universidade Estadual de Maringá, para efetuar visitas em suas lavouras, uma vez que estavam preocupados com a alta intensidade de doença, caracterizada por manchas foliares, que estava atingindo as plantas de capim-limão. Nas lavouras visitadas, os sintomas nas plantas consistiam de lesões foliares ferruginosas escuras, tendendo a negras, na forma de pústulas alongadas, com maior concentração na superfície abaxial das folhas, atingindo até $0,5 \mathrm{~cm}$ de comprimento e com presença de grande massa de esporos. As lesões se coalesciam, atingindo grande parte do limbo foliar, causando amarelecimento seguido de bronzeamento e seca das folhas (Figura 1A). Amostras de folhas doentes, com níveis diferenciados de idade e de severidade da doença, foram colhidas e examinadas em laboratório. A partir de observações ao microscópio diagnosticou-se tratar de uma ferrugem.

Duas amostras de folhas de capim-limão com sintomas de ferrugem (pústulas contendo urediniósporos e teliósporos) foram enviadas ao Instituto de Pesquisas Jardim Botânico do Rio de Janeiro, as quais receberam números de registro de entrada 
RB403039 e RB403040, para identificação do agente causal.

Por meio de exame ao microscópio óptico foram observados urediniósporos e teliósporos que apresentaram as seguintes características: urediniossoros predominantemente hipófilos, paralelos às nervuras, inicialmente cobertos pela epiderme e expostos depois, pulverulentos, de coloração canela a canela-escuros, amarelos pálidos nos soros mais velhos, até $1,5 \mathrm{~mm}$ comp., coalescentes; urediniósporos (Figuras 1C-D) obovóides a largamente elipsóides, finamente verrugosos, de coloração canela-claros a canela-escuros, (24-)26(-28) mm comp., (21-)22(-24) mm larg., paredes 2,0 a 2,5 $\mathrm{mm}$, poros germinativos 3-5 equatoriais a su- pra-equatoriais algumas vezes dispersos; pedicelos hialinos de parede fina e colapsando no hilo, raramente abaixo; paráfises se confundem com os pedicelos. Teliossoros tardios, a partir dos urediniossoros, pulvinados, castanho-escuros; teliósporos bicelulares (Figura 1B), largamente elipsóides, ligeiramente constritos no septo, lisos, de coloração castanha, (29-)33(-37) mm comp., (21-)24(-26) mm larg., 1,0 a 1,5 mm larg. lateral e 3,0 a 9,0 mm no umbo; pedicelos hialinos de parede fina e colapsando abaixo do hilo; mesósporos raros. De acordo com essas características diagnosticou-se Puccinia cymbopogonis Mass. (Kew Bull. Misc. Inform. 1911: 224).
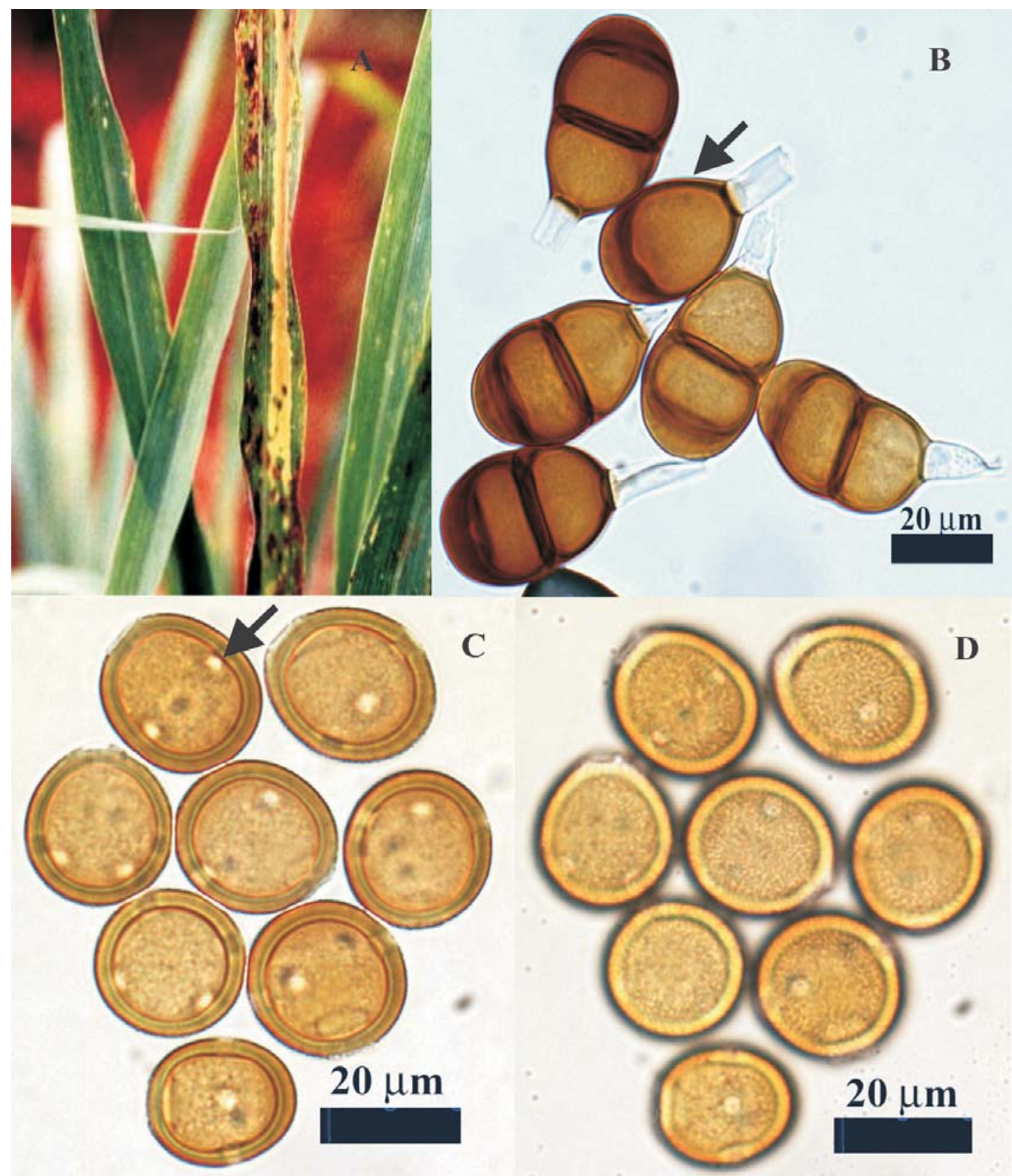

C

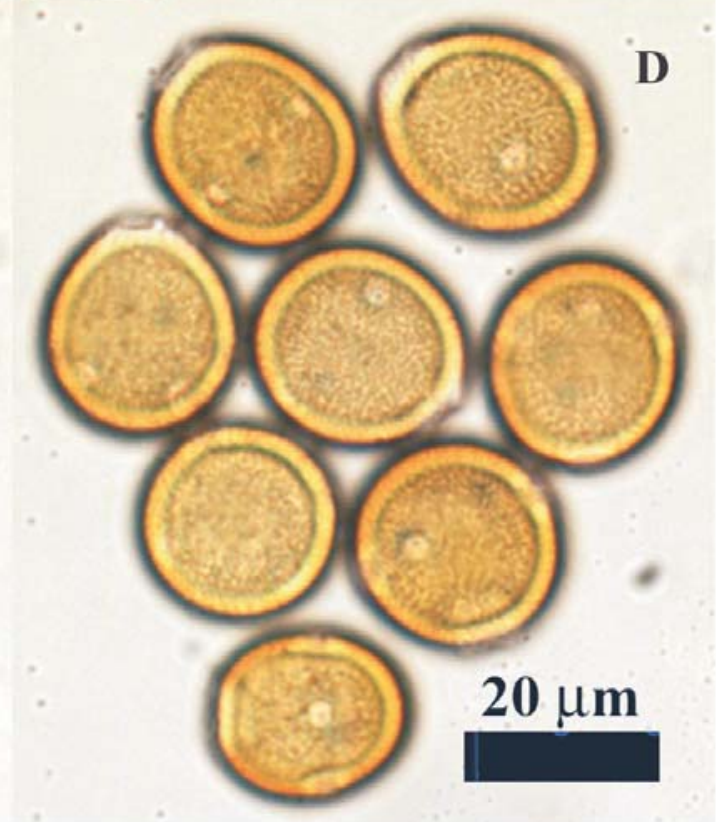

Figura 1. Folha de capim-limão com pústulas de Puccinia cymbopogonis (A). Esporos de P. cymbopogonis (RB403040) (B-D). Teliósporos - seta - mesósporo (B). Urediniósporos em vista mediana - seta - poros germinativos (C). Urediniósporos em vista superficial mostrando o padrão de ornamentação finamente verrugoso das paredes (D). 
P. cymbopogonis foi descrita pela primeira vez por Georg Edward Massee em Fyffe, Entebbe, Unganda, África em 1911 (1). Segundo o mesmo autor, o patógeno apresenta distribuição na região central e ao sul da África. Desde então, poucos registros da espécie, como na Austrália em 1978 (2), têm sido efetuados.

Outra ferrugem sobre o mesmo hospedeiro causada por $P u c$ cinia nakanishikii Dietel tem distribuição mais ampla, tendo sido registrada da África até a Índia, Ceilão, Nova Guiné, Filipinas, China e Japão (1) e, mais recentemente, foi registrada também no Hawai (3) e na Califórnia (4). Puccinia purpurea Cke., ferrugem mais comumente encontrada sobre sorgo (Sorghum spp.), também foi confirmada sobre capim-limão na Colômbia (5).

\section{AGRADECIMENTO}

Os autores agradecem ao Sr. Elenilton Souza (Produtor de Capim-limão) e, pelo apoio financeiro, ao CNPq, à FAPERJ e à Capes.

\section{REFERÊNCIAS BIBLIOGRÁFICAS}

1. Cummins, G.B. The rust fungi of cereals, grasses and bamboos. New York: Springer-Verlag, 1971. 570p.

2. Brown, J.S. Recent invasions of Australia and New Zealand by pathogenic fungi and counter measures. EPPO Bulletin, Auckland, v.14, p.417-428, 1984.

3. Gardner, D.E. Lemongrass rust caused by Puccinia nakanishikii in Hawaii. Plant Disease, St. Paul, v.69, n.12, p.1100, 1985.

4. Koike, S.T. Rust disease on lemongrass in California. Plant Disease, St. Paul, v.83, n.6, p. 304, 1999.

05. Pardo-Cardona, V.M. La roya del limoncillo, una nueva enfermedad para Colombia y Sur America. Fitopatologia Colombiana, medellin v.23, n.1/2, p.43-44, 1999. 